\title{
Refractory status epilepticus occurred at the end of sevoflurane anesthesia in patient with epilepsy
}

\author{
Min Ji Kim, Dong Gun Lim, and Jin-Seok Yeo \\ Departement of Anesthesiolgy and Pain Medicine, School of Medicine, Kyungpook National University, Daegu, Korea
}

Status epilepticus (SE) is a single seizure or recurrent seizures lasting for more than 30 minutes, in which the consciousness is not regained. Refractory status epilepticus (RSE) is defined as status epilepticus that continues despite treatment with benzodiazepines and one antiepileptic drug [1].

The incidence of seizure activity in patients with epilepsy associated with anesthesia is 3.4\% [2], but RSE is rarely reported during emergence of anesthesia. We describe a patient with epilepsy who developed RSE during and after emergence from anesthesia.

A 5-year-old, $22 \mathrm{~kg}$, female patient was presented for ventilating tube insertion. She had a history of traumatic subarachnoid hemorrhage, diffuse brain injury and basal skull fracture 2 years ago. She was diagnosed with simple partial seizure 14 months ago and had been treated with valproic acid $240 \mathrm{mg} /$ day. She did not show seizure activity for 1 year. Preoperative valproic acid concentration was $53.9 \mathrm{ug} / \mathrm{ml}$ and electroencephalogram (EEG) was normal. Other preoperative evaluations were within normal value, but she showed rhinorrhea.

On the day of surgery, she received valproic acid $10 \mathrm{mg} / \mathrm{kg} \mathrm{IV}$ during nil per os (NPO). The patient was taken to the operation room. The heart rate, noninvasive blood pressure, oxygen saturation and BIS (A-2000, Asepct Medical Systems Inc, Natick, MA, USA) were continuously monitored. After preoxygenation, induction of anesthesia was performed using thiopental sodium $110 \mathrm{mg}$ iv and rocuronium bromide $10 \mathrm{mg}$ iv. After intubation, anesthesia was maintained with sevoflurane in an air-oxygen mixture (fraction inspired oxygen concentration $=0.5$ ). Arterial oxygen saturation remained greater than $98 \%$ during the intraoperative course. No episodes of hypoxia occurred during the procedure.

As the patient began to emerge from anesthesia (BIS value was approximately 70), focal clonic movement of the right face and right arm was occurred. We suspected seizure and gave her midazolam $4 \mathrm{mg}$ iv, but focal clonic movement did not stop. Therefore, we gave her phenytoin $20 \mathrm{mg} / \mathrm{kg}$ iv for 20 minutes and started desflurane inhalation (end-tidal concentration was $8 \%$ ). Her seizure activity ceased and BIS was below 10 . We discontinued desflurane and tried to emerge her from anesthesia. After 10 minutes, she started focal seizure again (BIS values was 65). We started phenobarbital infusion $20 \mathrm{mg} / \mathrm{kg}$ for 20 minutes.

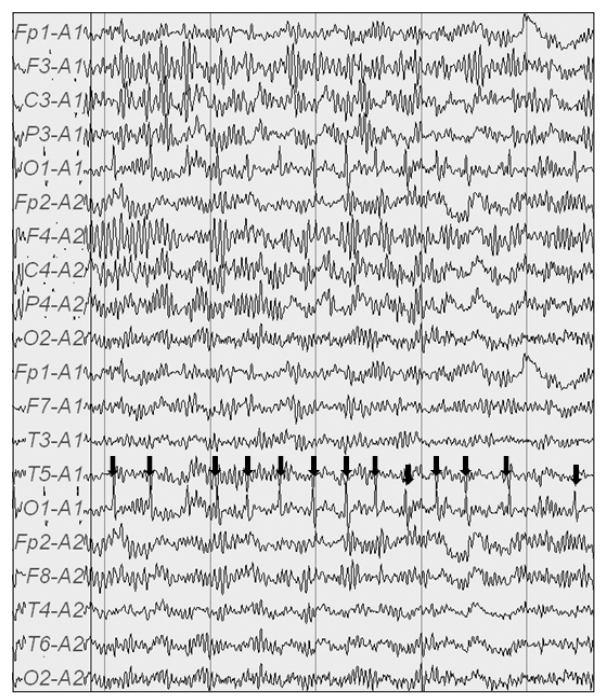

Fig. 1. Electroencephalogram in the intensive care unit shows rhythmic or periodic spikes in the left occipital region. Arrows are spike.

Corresponding author: Jin-Seok Yeo, M.D., Departement of Anesthesiolgy and Pain Medicine, School of Medicine, Kyungpook National University, 130, Dongdeok-ro, Jung-gu, Daegu 700-721, Korea. Tel: 82-53-420-5863, Fax: 82-53-426-5863, E-mail: painfree@gmail.com (c) This is an open-access article distributed under the terms of the Creative Commons Attribution Non-Commercial License (http:// creativecommons.org/licenses/by-nc/3.0/), which permits unrestricted non-commercial use, distribution, and reproduction in any medium, provided the original work is properly cited. 
Her seizure activity did not stop after phenobarbital infusion. We planned to move her to the intensive care unit.

In the intensive care unit, we checked for complete blood count, electrolyte, arterial blood gas, urine analysis, liver function test, EEG and serum valproic acid level. EEG showed rhythmic or periodic spikes in the left occipital region and was suggestive of SE (Fig. 1). Serum valproic acid level was $36.2 \mathrm{ug} / \mathrm{ml}$. Other laboratory values were within normal limit. We infused valproic acid $10 \mathrm{mg} / \mathrm{kg}$ for 1 hour. Focal seizure was stopped and she regained consciousness. She was discharged 2 days after without any other complication.

General anesthesia may increase seizure activity, such as withholding antiepileptic drugs while maintaining NPO status prior to surgery, sleep deprivation, and use of proconvulsant medications. Sevoflurane anesthesia causes epileptiform EEG activity and produce clinical evidence of seizures in patients with or without a history of epilepsy. Hypercarbia and hypoventilation during emergence from anesthesia may increase seizure susceptibility and prolong seizure duration [3].
Lowered antiepileptic drug level is a common cause of status epilepticus. In this case, postoperative serum valproic acid concentration was lower than preoperative level, despite of preoperative iv administration. There are two possible causes of lowered valproic acid level. First, the patient missed one or two dose of antiepileptic drugs after admission without notifying the medical staff. Second, phenobarbital and phenytoin are potent hepatic enzyme inducers. They may increase valproic acid metabolism and decrease plasma concentration [4].

Treatment of RSE starts immediately with additional agents. Most often recommended drugs for use as a continuous infusion are midazolam, propofol, pentobarbital and thiopental. Continuous drug infusion in RSE is titrated to achieve an EEG burst suppression pattern. If continuous EEG monitoring is not available, BIS monitor can be used to guide titration of anesthetics in RSE [5].

In conclusion, we report a case of RSE during emergence of general anesthesia that may be caused by sevoflurane anesthesia and lowered antiepileptic drug concentration.

\section{References}

1. Mayer SA, Claassen J, Lokin J, Mendelsohn F, Dennis LJ, Fitzsimmons BF. Refractory status epilepticus: frequency, risk factors, and impact on outcome. Arch Neurol 2002; 59: 205-10.

2. Niesen AD, Jacob AK, Aho LE, Botten EJ, Nase KE, Nelson JM, et al. Perioperative seizures in patients with a history of a seizure disorder. Anesth Analg 2010; 111: 729-35.

3. Crawford CD, Butler P, Froese A. Arterial PaO2 and $\mathrm{PaCO} 2$ influence seizure duration in dogs receiving electroconvulsive therapy. Can J Anaesth 1987; 34: 437-41.

4. Davis R, Peters DH, McTavish D. Valproic acid. A reappraisal of its pharmacological properties and clinical efficacy in epilepsy. Drugs 1994; 47: 332-72.

5. Musialowicz T, Mervaala E, Kälviäinen R, Uusaro A, Ruokonen E, Parviainen I. Can BIS monitoring be used to assess the depth of propofol anesthesia in the treatment of refractory status epilepticus? Epilepsia 2010; 51: 1580-6. 